\title{
Maleated Polypropylene as Coupling Agent for Polypropylene Composites Reinforced with Eucalyptus and Pinus Particles
}

\author{
Rômulo Maziero, ${ }^{\mathrm{a}, \mathrm{b}, *}$ Kinglston Soares, ${ }^{\mathrm{c}}$ André I. Filho, ${ }^{\mathrm{b}}$ Adonias R. Franco Jr., ${ }^{\mathrm{b}}$ and \\ Juan C. C. Rubio ${ }^{\text {a }}$
}

\begin{abstract}
Waste from the processing of hardwood and coniferous wood generated in the timber industries is difficult to dispose of and can cause considerable environmental impacts, such as soil and groundwater contamination. In this context, composites with varying concentrations of polypropylene, maleated polypropylene, and particulate Eucalyptus and Pinus waste were produced in a twin screw extruder and injection molded as test bodies for tensile and flexural tests. The morphology of the composites was investigated via scanning electron microscopy. The thermal properties were identified through differential scanning calorimetry. The tensile and flexural results for the two waste formulations indicated that the addition of vegetable fillers increased the modulus of elasticity and bending, and the compatibilizer provided increased resistance to stress and maximum deflection. The scanning electron micrographs illustrated the wetting of the cellulosic charge by the thermoplastic polymer with the compatibilizer, which corroborated the possible occurrence of an esterification reaction and hydrogen bonding interactions in the matrixparticle interface. The incorporation of waste in the composite resulted in the reduction of the degree of crystallinity of polypropylene, regardless of the use of the compatibilizer. This was explained by the barrier capacity of the charge, which prevented the growth of the crystals.
\end{abstract}

Keywords: Composites; Polypropylene; Maleated polypropylene; Solid waste; Wood

Contact information: a: Post-Graduate Program in Mechanical Engineering, Federal University of Minas Gerais, 6627 Av. Antonio Carlos, 31270-901, Belo Horizonte, Minas Gerais, Brazil; b: Post-Graduate Program in Metallurgical and Materials Engineering, Federal Institute of Education, Science and Technology of Espirito Santo, 1729 Av. Vitoria, 29040-780, Vitoria, Espirito Santo, Brazil; c: PostGraduate Program in Sustainable Technologies, Federal Institute of Education, Science and Technology of Espirito Santo, 1729 Av. Vitoria, 29040-780, Vitoria, Espirito Santo, Brazil;

*Corresponding author: maziero@ufmg.br

\section{INTRODUCTION}

Timber industry solid waste accumulation is a continuous process that requires storage spaces that do not pose a risk of fire hazard. However, part of this volume of waste is used by small farmers in breeding and soil fodder crops, as well as by briquette industries, fertilizer companies, and potteries in the generation of energy. Wood waste can also be used as reinforcement in the manufacturing of wood-plastic composites, commercially known as WPCs.

Wood-plastic composites are widely marketed in the United States and Europe in construction, automotive, and structural applications. In Brazil, the use of this product is still low, although Brazil is one of the largest producers of planted forests in the world, generating large volumes of wood waste that can be used in the preparation of WPCs. 
Approximately 47 million tons of wood waste from the wood processing and forest harvesting industries were generated in 2015, of which 33 million tons $(70.5 \%)$ were generated by forestry activities and 13.8 million tons (29.5\%) by industrialists (IBÁ 2017). However, the distance between the sawmills and the processing industries, as well as the lack of knowledge of the characteristics of the waste generated in the mechanical processing of wood, prevents the increase of the production of WPCs (Clemons 2002). Therefore, knowing the properties of the waste and using them properly is important to produce ecologically responsible products with reduced cost. These materials can have advantages in the production of components with greater dimensional stability, lower weight, and easy processing (Malkapuram et al. 2009; Leong et al. 2014).

Waste from species such as Eucalyptus spp. and Pinus spp. are interesting alternatives for reinforcements in polymer matrix composites. The genus Eucalyptus presents a great diversity of qualities, including high forest productivity, adaptability to diverse environments, and fast growth. The genus Pinus has low density, fast and easy growing cycles, and a shorter processing time compared to other species. The automotive sector was first to use vegetal wastes of the genera Eucalyptus and Pinus in composites for the manufacture of composite pieces with an approximate weight reduction of $40 \%$ when compared with fiberglass (Leão et al. 2009). The use of wood waste as reinforcement in thermoplastic resins has been studied by many authors (Yamaji and Bonduelle 2004; Bledzki et al. 2005; Paes et al. 2011; Dai and Fan 2014). The inclusion of particulate wood waste in a thermoplastic matrix provides consistent results for commercial use (Hillig et al. 2008) and low cost in relation to inorganic loads, such as fiberglass, talc, $\mathrm{CaCO}_{3}$, and mica, among others. According to López-Manchado et al. (2002) and Parente and Pinheiro (2008), the addition of lignocellulosic charges in a thermoplastic matrix increases the modulus of elasticity and attenuates time-dependent phenomena such as creep and relaxation.

Today, it is common to manufacture WPCs with polypropylene (PP) resin thermoplastic and wood, using a compatibilizer to improve adhesion between the matrix and the load. Polypropylene is widely exploited in a variety of applications that when combined with favorable economic conditions and excellent thermal and mechanical properties has encouraged a rapid expansion in the use of this material (Rosário et al. 2011). The maleic anhydride-modified polypropylene additive (PPMA) is one of the most widely used in WPCs because it presents an excellent adhesion between the matrix-particle interface.

Results from the literature show that the use of this compatibilizer improves the mechanical properties of the composites produced (Stark 1999; Albano et al. 2001; Keener et al. 2004; Kim et al. 2008; Yeh et al. 2013; El-Sabbagh 2014; Haq and Srivastava 2017). In this context, the main objective of this work is to compare the mechanical, morphological, and thermal properties of reinforced composites with planted forest waste (Eucalyptus spp. and Pinus spp.) in a PP matrix with and without PPMA coupling agent. In the literature no work was found comparisons between these species no treatment using PPMA in the same matrix PP.

This research contributes to the development of new wood-plastic composites and the reduction of environmental impact caused by the disposal of Eucalyptus and Pinus waste. 


\section{EXPERIMENTAL}

\section{Materials}

The matrix used was the virgin isotactic homopolymer polypropylene (PP-Ho) in granules, grade $\mathrm{H} \mathrm{301}$, flow index IF $=10 \mathrm{~g} / 10 \mathrm{~min}\left(230{ }^{\circ} \mathrm{C} / 2.16 \mathrm{~kg}\right)$, and a density of $0.905 \mathrm{~g} \mathrm{~cm}^{-3}$ (Braskem, Sao Paulo, Brazil). The compatibilizer used was PPMA in granules, IF $=112 \mathrm{~g} / 10 \mathrm{~min}\left(190{ }^{\circ} \mathrm{C} / 2.16 \mathrm{~kg}\right)$, a density of $0.910 \mathrm{~g} \mathrm{~cm}^{-3}$, and $1 \%(\mathrm{w} / \mathrm{w})$ maleic anhydride (MA) (Addivant, Danbury, USA). In its dispersed phase (ASTM D192118 and ISO 13322-14) as unmixed waste, granulometries were used in the range of 0.15 $\mathrm{mm}$ to $1.20 \mathrm{~mm}$ of Eucalyptus spp. (aspect ratio 0.4) and Pinus spp. (aspect ratio 0.5) without chemical treatment, a density of $0.11 \pm 0.01 \mathrm{~g} \mathrm{~cm}^{-3}$ and $0.20 \pm 0.01 \mathrm{~g} \mathrm{~cm}^{-3}$ with moisture contents of $9.9 \pm 0.9 \%$ and $7.0 \pm 0.2 \%$ for Eucalyptus and Pinus, respectively.

\section{Methods}

Preparation of WPCs

The composites were prepared in a Werner-Pfleiderer ZSK-30 L/D 35 corrotative interpenetrating modular twin screw extruder (Coperion GmbH, Stuttgart, Germany) with a $100 \mathrm{rpm}$ screw speed. Gravimetric feeders (Coperion K-Tron, Salina, USA) were used at a feed rate of $1.5 \mathrm{~kg} \mathrm{~h}^{-1}$ (side hopper) feed and the feed rate of the polymer (main funnel) was varied to maintain the wood particles at concentrations of $10 \%, 20 \%, 30 \%$, and $40 \%$ w/w. The use of PPMA at 1\%, 5\%, and $10 \%$ was determined according to the substitution of the equivalent quantity of polypropylene. For some formulations, only the concentrations of $20 \%$ and $40 \%$ w/w wood for $1 \%$ and $10 \% \mathrm{w} / \mathrm{w}$ of PPMA were tested, in order to evaluate the behavior of the largest intervals of each fraction. Figure 1 shows the mounting of the thread profile and the temperatures used in the six heating zones.

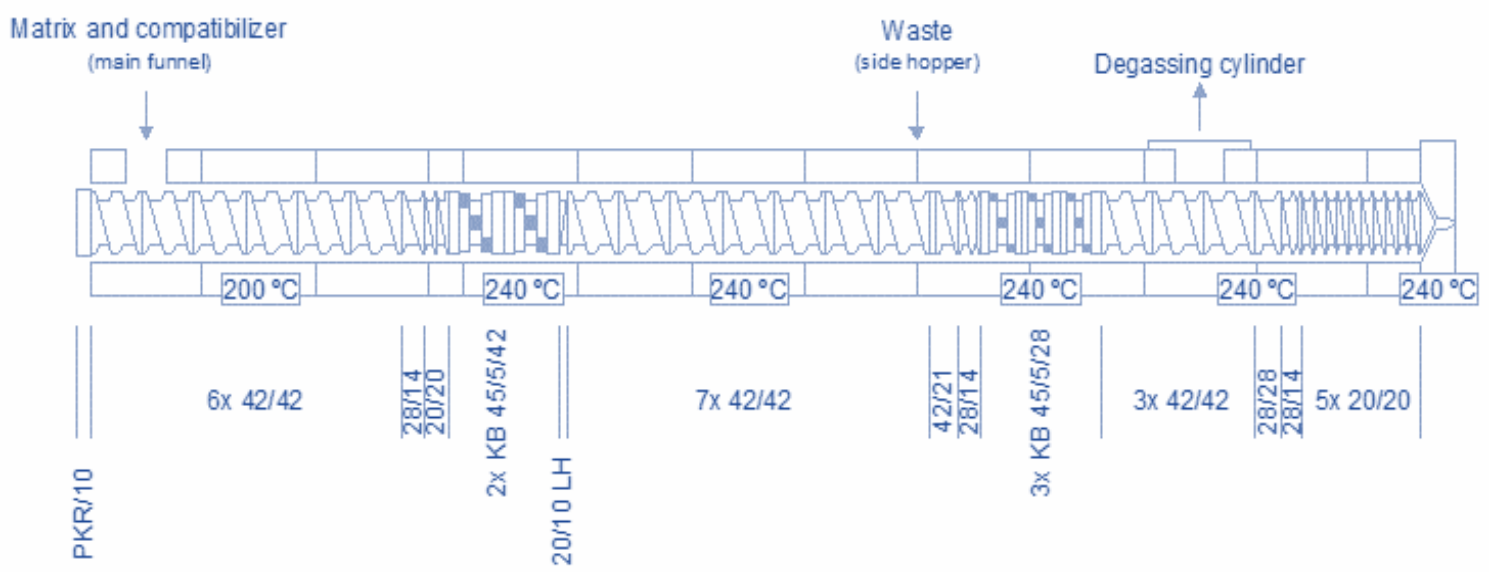

Fig. 1. Schematic of the thread profile and extrusion temperatures

Subsequently, specimens were molded from the extruded granules and oven-dried under vacuum at $80^{\circ} \mathrm{C}$ for $12 \mathrm{~h}$ in an injector Arburg Allrounder (270V/300-120 L/D 30; Arburg GmbH, Loßburg, Germany) with the temperature profile of the feed to the injection nozzle at $210^{\circ} \mathrm{C}, 215^{\circ} \mathrm{C}, 225^{\circ} \mathrm{C}, 230^{\circ} \mathrm{C}$, and $235^{\circ} \mathrm{C}$ with an injection pressure of 450 bar. 


\section{Mechanical tests}

The tensile and flexure tests were performed in an EMIC universal test machine (DL 10000/700; Instron, Sao Jose dos Pinhais, Brazil). The tensile test followed the ASTM D638-14 (2014) standard using specimens with 'Type I geometry', a 1000 kgf load cell, $50-\mathrm{mm}$ extensometer, and constant speed for $5 \mathrm{~mm} \mathrm{~min}^{-1}$ assay. The flexural test followed the ASTM D790-10 (2010) standard using specimens with 'Procedure A' geometry, a 200 $\mathrm{kgf}$ load cell, and a deformation rate of $1.36 \mathrm{~mm} \mathrm{~min}^{-1}$.

\section{Scanning electron microscopy (SEM)}

The adhesion between the matrix-particle interfaces was verified by means of the fracture surface of samples after tensile test. The observations were confirmed using a ZEISS $^{\circledR}$ scanning electron microscope (EVO MA10; Carl Zeiss AG, Feldbach, Switzerland). The samples of the composites were fixed to a support with the help of double-sided self-adhesive carbon tape, metallized with a gold film, and analyzed at an acceleration voltage of $25 \mathrm{kV}$.

\section{Differential scanning calorimetry (DSC)}

The samples were extracted from fractured traction bodies for thermal analysis. The tests followed ASTM D3418-12 (2012) standard and were conducted on DSC equipment, specifically a NETZSCH STA 449 F3 Jupiter ${ }^{\circledR}$ (NETZSCH-Gerätebau GmbH, Selb, Germany), at a heating rate of $10{ }^{\circ} \mathrm{C} \mathrm{min}-1$ in the temperature range of $25{ }^{\circ} \mathrm{C}$ to $230{ }^{\circ} \mathrm{C}$ in an alumina crucible, inert argon atmosphere as the purge gas $\left(60 \mathrm{~mL} \mathrm{~min}^{-1}\right)$, and protection $\left(20 \mathrm{~mL} \mathrm{~min}^{-1}\right)$ at $0.5 \mathrm{bar}$. Subsequently, the samples were cooled to $25^{\circ} \mathrm{C}$ and heated again under the same conditions. The samples were submitted to two heating cycles. The first cycle was to eliminate the thermal history of the material from extrusion and injection and the second was to analyze the thermal characteristics without influence of the processing conditions. The percentage of crystallinity of the polypropylene (Eq. 1) in the composites was calculated using $\Delta H_{m}^{o} 100 \%=209 \mathrm{~J} \mathrm{~g}^{-1}$ as reference (Hirayamaa et al. 2017),

$$
X_{c} \%=\frac{\Delta H_{m}}{\Delta H_{m}^{o} \cdot(1-x)} \cdot 100
$$

where $\Delta H_{m}^{o} 100 \%$ is the melt enthalpy $\left(\mathrm{J} \mathrm{g}^{-1}\right)$ for crystalline PP and $x$ represents the weight fraction of the particle in the composite. The values of melt temperature $\left(T_{\mathrm{m}}\right)$, melt enthalpy of samples $\left(\Delta H_{\mathrm{m}}\right)$, and percent crystallinity $\left(X_{\mathrm{c}}\right)$ were taken from the curve of the second heating cycle.

\section{RESULTS AND DISCUSSION}

The mean values obtained in the tensile tests for the PP/PPMA/Eucalyptus and PP/PPMA/Pinus composites are shown in Figs. 2, 3, and 4. 

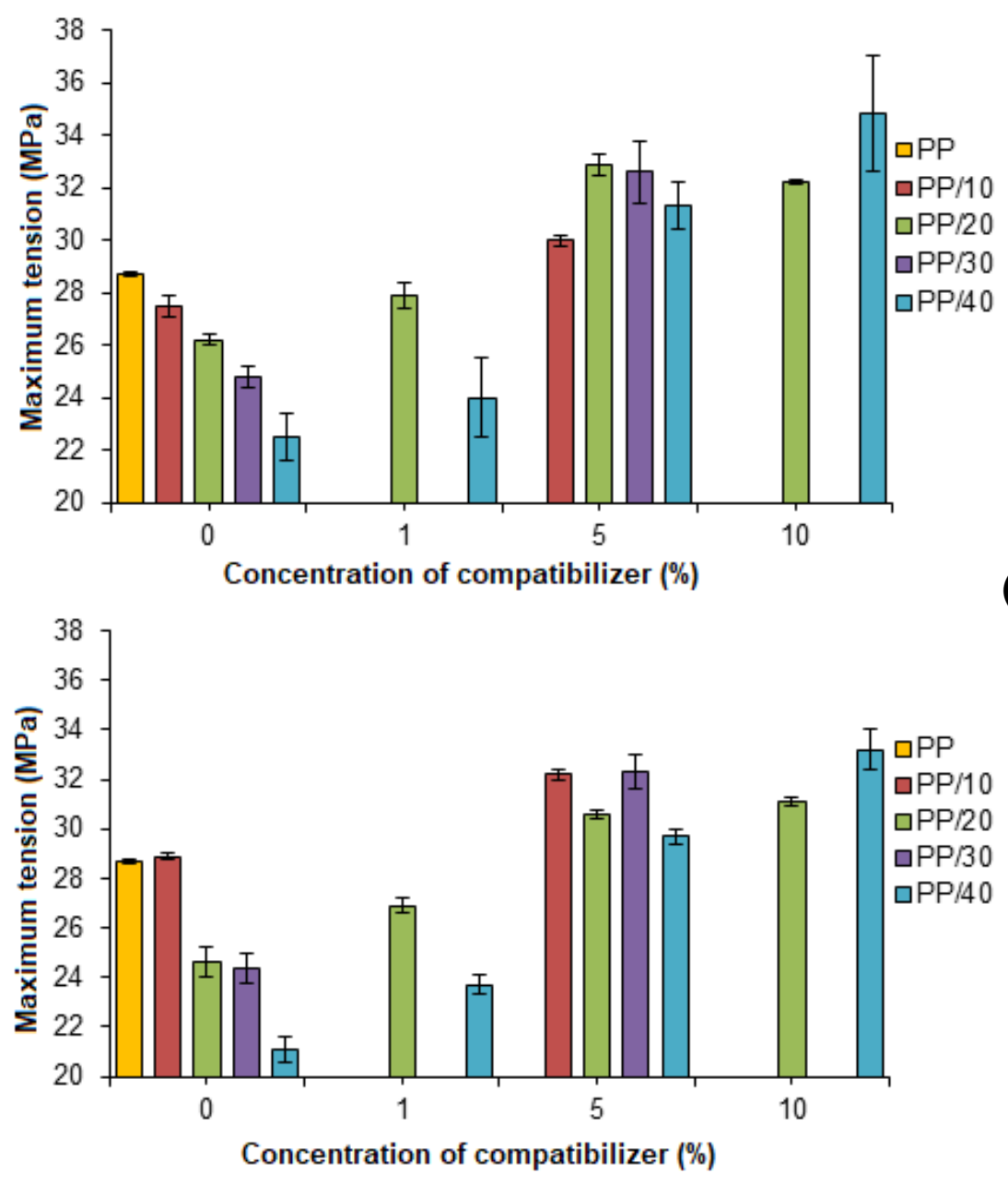

(a)

(b)

Fig. 2. Maximum tension variation for polypropylene and compatibilized and not compatibilized composites of PP/Eucalyptus (a) and PP/Pinus (b)

Particle-particle interaction, which is a combination of particle agglomeration and matrix-particle interaction, determines macroscopic behavior and material performance of a composite (Pukánszky 2005). Thus, it is observed in Fig. 2 that the maximum stress was reduced with the addition of wood particles in the polymer matrix, due to the possible propagation of cracks inside the composite caused by clusters of particles that acted as stress concentrators and, in this way, resulted in low mechanical strength of the material. Another indication was related to the weak matrix-reinforcement interaction caused by the lack of wettability between the reinforcement, which has a polar nature, and the polymer matrix, which has an apolar nature. It was noted that the PP/10\%Pinus formulation in comparison with the thermoplastic matrix showed no decrease with the incorporation of the waste. This may have been related to the distribution of the charge in the matrix.

It was also observed that the same behavior of decline in the maximum tension with the addition of waste with $1 \%$ and $5 \%$ compatibilizer was observed for the PP/Eucalyptus composite. Unlike the PP/Eucalyptus and PP/Pinus composites with $10 \%$ compatibilizer, no decrease in tensile strength was observed with the waste concentration, in addition to a marked increase in the maximum stress supported by the material, in relation to the polypropylene matrix. 
The addition of the PPMA compatibilizer led to a remarkable increase in the maximum stress when compared to the PP/Eucalyptus and PP/Pinus composites for the same mass waste concentration. This was associated with the possible improvement in the adsorption and interfacial adhesion as a function of the decrease in the surface tension between the phases that allowed a better transfer of tension between the matrix and the reinforcement. Thus, if the reinforcement percentage in the matrix is higher, the stress level supported by the composite will be higher as a consequence of the larger compatibilized matrix-particle interfacial area. Another possible factor for the improvement in wettability of solid surfaces and the consequent increase in maximum composite stress was due to the probable reaction of esterification and hydrogen bonding of cellulose with maleic anhydride modified polypropylene. According to Correa et al. (2003), this is due to a possible occurrence of mechanical anchoring or chemical interactions between the anhydride groups and the hydroxyl groups of the cellulose at the polymer-wood interface, promoting the effective transfer of forces from the matrix to the dispersed phase.

The PP/10\%PPMA/20\%Eucalyptus and PP/10\%PPMA/20\%Pinus showed an approximate $25 \%$ increase in the maximum stress, and PP/10\%PPMA/40\%Eucalyptus and $\mathrm{PP} / 10 \% \mathrm{PPMA} / 40 \%$ Pinus exhibited an approximate 55\% increase in the maximum stress, compared to the same not compatibilized formulations. The results for the PP/Eucalyptus and PP/Pinus composites with 1\% and 5\% of PPMA in relation to the not compatibilized composites and those with 10\% PPMA presented interposed values. It was observed that the use of $10 \%$ compatibilizer was enough to avoid losses in the tensile strength of the polymer, even when $40 \%$ of wood particles were added in the PP/PPMA/Eucalyptus and PP/PPMA/Pinus formulations.

The elongation of the polymer is not shown in Fig. 3 because no rupture of the test specimens occurred at the extension limit of the claws of the test equipment. For all formulations, the ductility of the matrix decreased with the addition of waste, as the cellulosic load had high stiffness and low deformation. Lopez-Manchado et al. (2002) found that the addition of organic charges in a composite reduces the elongation at rupture because the fillers act as a reinforcing agent in the polypropylene, reducing the mobility of the polymer chains of the matrix, making the composite hard. 

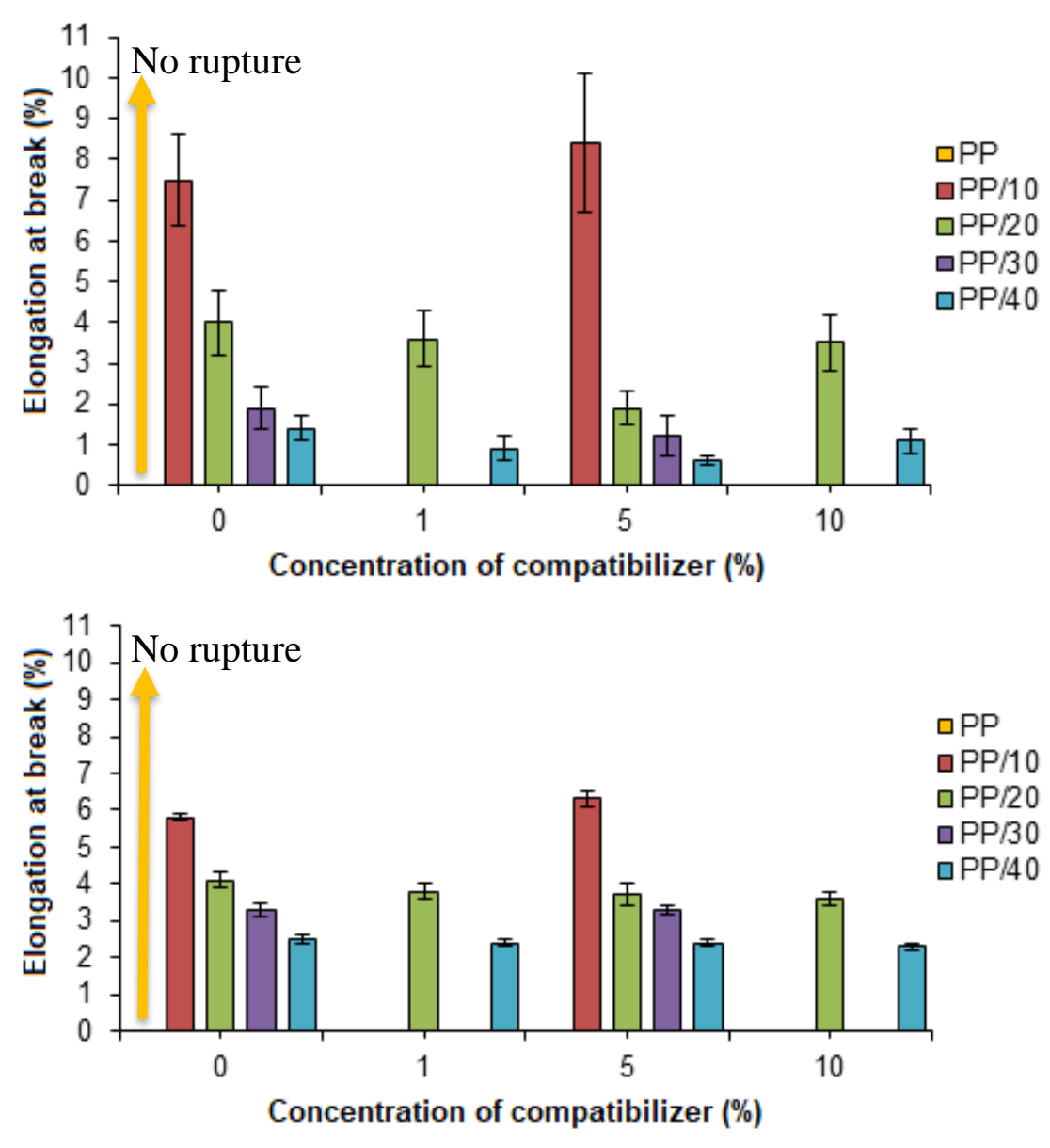

(a)

Fig. 3. Variation of elongation at break for polypropylene and compatibilized and not compatibilized composites of PP/Eucalyptus (a) and PP/Pinus (b)

In the composite materials, voids were formed during phase processing, which, in addition to acting as voltage concentrators, narrowed the cross-section in which the force was applied. The concentration of particles in the composites also acted as stress concentrators, causing material rupture with a lower deformation.

The addition of compatibilizer had no remarkable influence on the elongation and also did not produce noticeable effects on the modulus of elasticity of some formulated composites, but the increase in the modulus was evident with the increased concentration of the load, as shown in Fig. 4. 

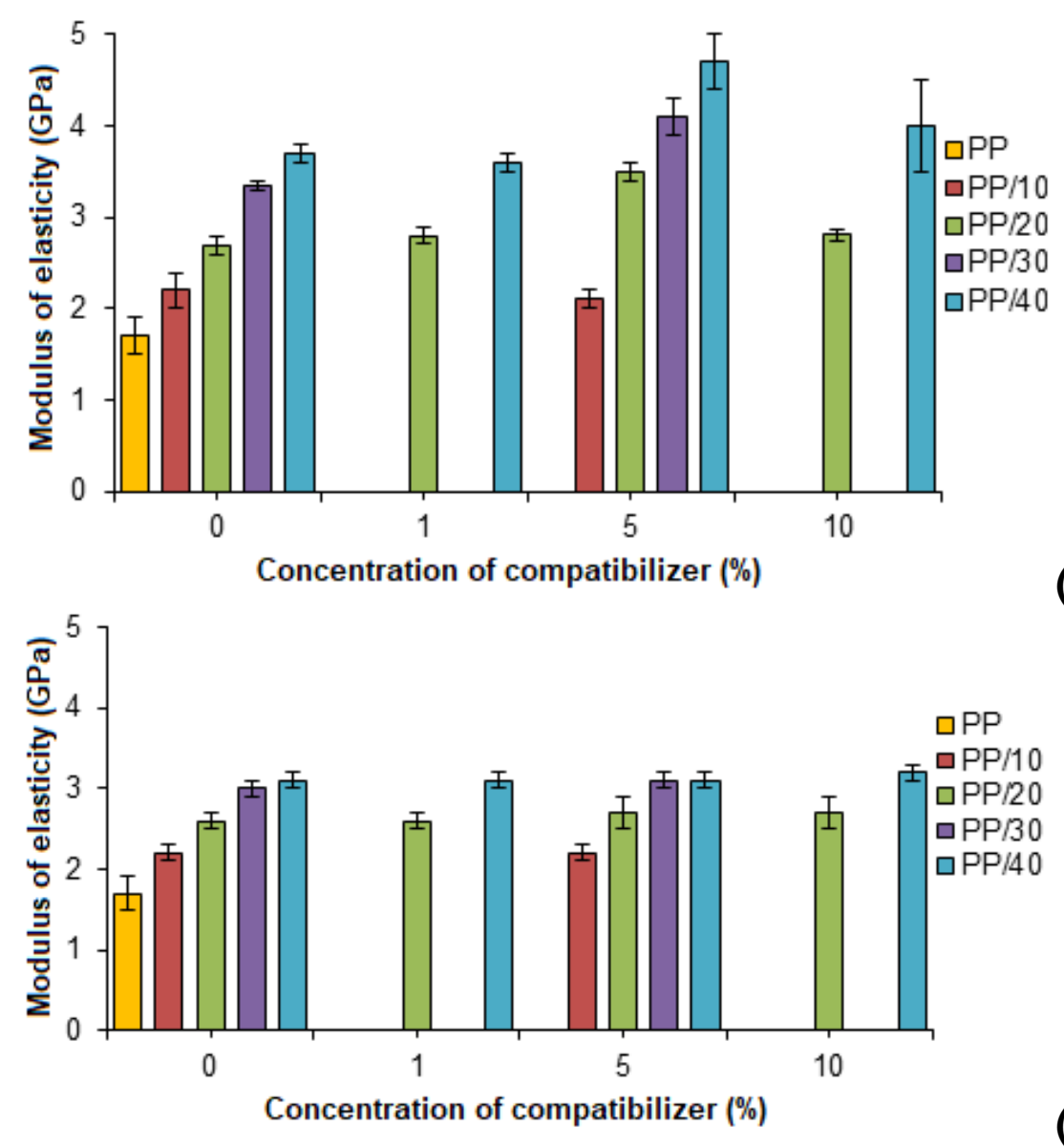

(a)

(b)

Fig. 4. Variation of modulus of elasticity for polypropylene and compatibilized and not compatibilized composites of PP/Eucalyptus (a) and PP/Pinus (b)

Polymer matrix composite materials usually have a higher modulus of elasticity than the matrix polymer. Thus, Fig. 4a shows that the addition of Eucalyptus particles in the thermoplastic matrix increased the elastic modulus approximately $30 \%, 60 \%, 95 \%$, and $115 \%$ with the addition values of $10 \%, 20 \%, 30 \%$ and $40 \% \mathrm{w} / \mathrm{w}$ of waste, respectively, in the compositions without compatibilizer.

Figure $4 \mathrm{~b}$ illustrates that an incorporation of Pinus particles in the matrix led to an increased modulus; this was expected because the tendency of composite materials is to increase stiffness as a higher percentage of residue in the matrix is added as reinforcement. The gains in the modulus were approximately $30 \%, 55 \%, 75 \%$, and $80 \%$ for values of $10 \%$, $20 \%, 30 \%$, and $40 \% \mathrm{w} / \mathrm{w}$ of particulates, respectively, in the not compatibilized formulations.

According to Caraschi and Leão (2002), the composites have a higher modulus of elasticity with respect to the polymers because the incorporated dispersed phase has higher stiffness than the matrix and acts as a barrier to the mobility of the polymer chains of the polymer, thus avoiding deformation. Therefore, the increase in the modulus of elasticity via the incorporation of added waste was already expected due to the greater limitation to the deformation of the polymer. Studies have shown an increase in the modulus of elasticity with the addition of wood waste in a polypropylene matrix when compared to the polymer matrix (López-Manchado et al. 2002). 
The results showed that there was influence in the modulus of tensile elasticity of polypropylene composites with $20 \%, 30 \%$, and $40 \%$ w/w of Eucalyptus waste with $5 \%$ compatibilizer, due to a better transfer of the loading between the polymer matrix and dispersed phase. This result was in agreement with those obtained by Nuñez et al. (2003) and Qiu et al. (2003) in studies on compatibilization systems of PP/wood particles. An indication of matrix-particle interfacial interaction in mixtures with $20 \%$ and $40 \%$ of Eucalyptus waste that contained $1 \%$ and $10 \%$ of PPMA was observed, but without modulus increase. The presence of the compatibilizer did not have noticeable effects on the elastic modulus under traction of the PP/Pinus composites. Similar results obtained by Yeh et al. (2013) showed that the modulus of elasticity did not vary with the addition of compatibilizer PPMA in the PP composite/wood particles. Probably due to poor wettability of substrate with matrix-PPMA.

Figures 5, 6, and 7 show the average values obtained in the PP/PPMA/Eucalyptus and PP/PPMA/Pinus composite bending tests.
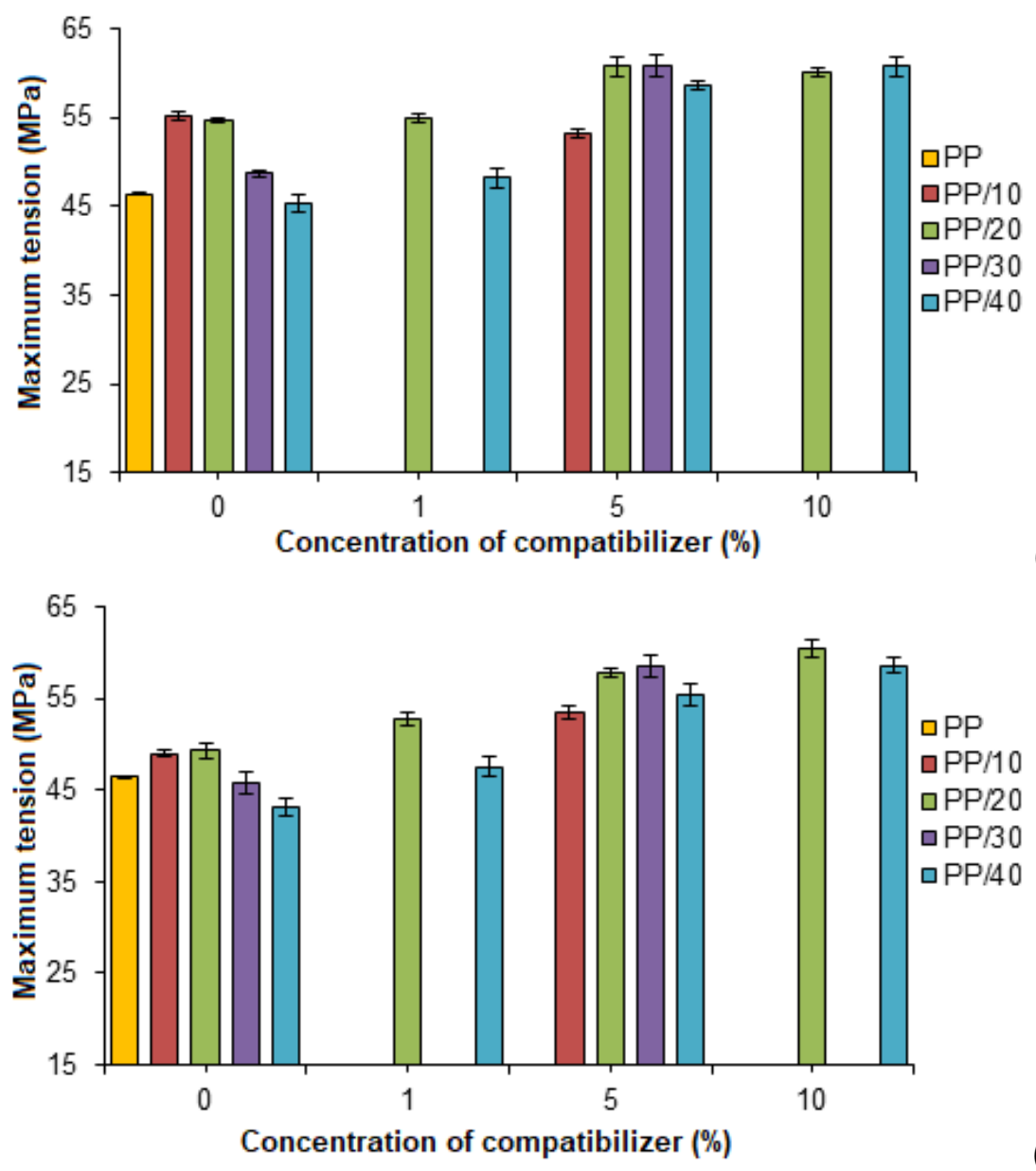

(a)

(b)

Fig. 5. Maximum tension variation for polypropylene and compatibilized and not compatibilized composites of PP/Eucalyptus (a) and PP/Pinus (b) 

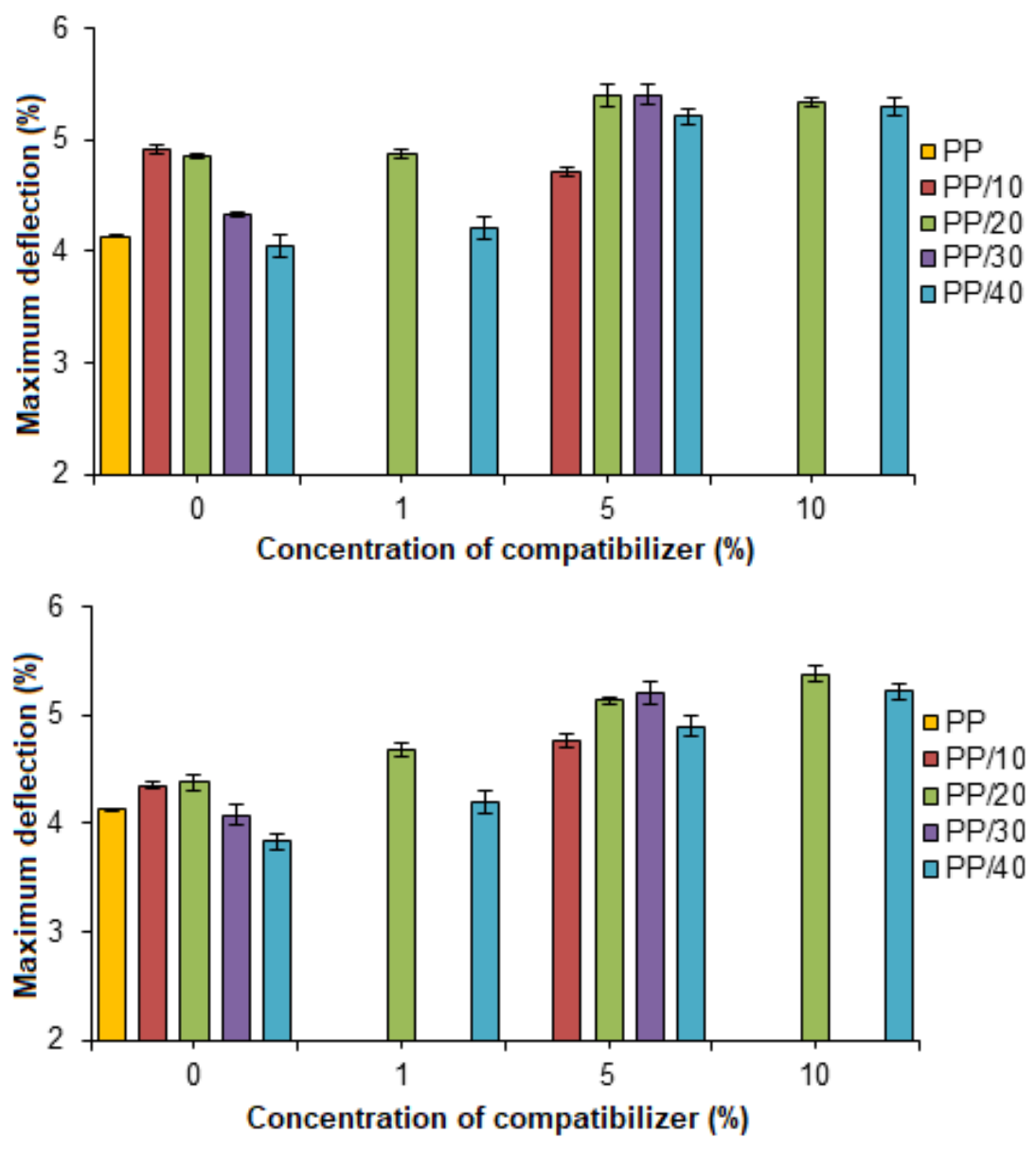

(a)

(b)

Fig. 6. Variation of maximum deflection for polypropylene and compatibilized and not compatibilized composites of PP/Eucalyptus (a) and PP/Pinus (b)

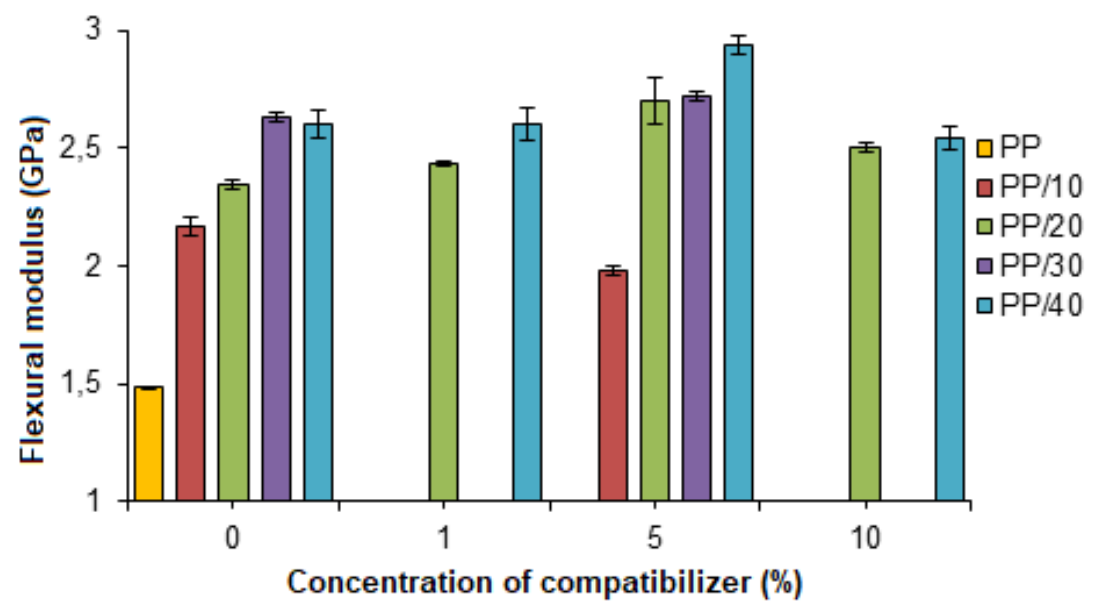

(a) 


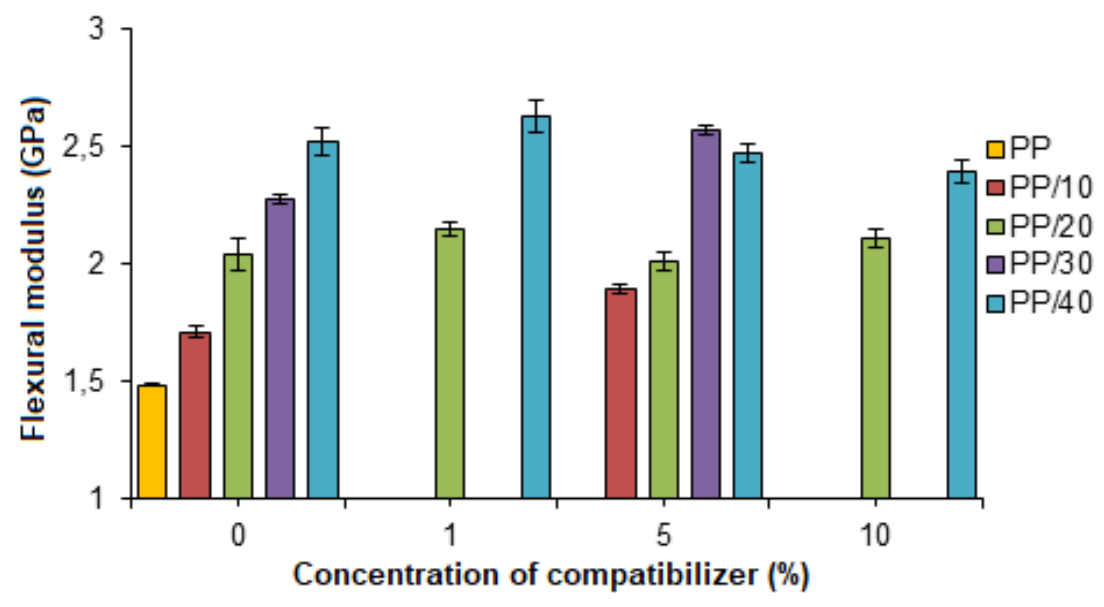

(b)

Fig. 7. Variation of flexural modulus for polypropylene and compatibilized and not compatibilized composites of PP/Eucalyptus (a) and PP/Pinus (b)

The results showed that as the waste levels increased, there was a decrease in the value of tension and maximum deflection. This was attributed to a low dispersion and high stiffness of the particles. The remarkable increase in stiffness was verified with the addition of Eucalyptus and Pinus waste, as indicated by the increase in modulus of elasticity in traction and bending. This result was in agreement with Dai and Fan (2014). For the $\mathrm{PP} /$ Eucalyptus composites, the approximate gains with the addition of wood particles were in the following order: $20 \%$ at the maximum stress for the PP/10\% waste, $20 \%$ at the maximum deflection for the PP/10\%waste, and $75 \%$ in the modulus of flexure for PP/40\%waste, without compatibilizer. The PP/Pinus composites obtained smaller gains than the PP/Eucalyptus composites, with values of $5 \%$ in the maximum tension for the $\mathrm{PP} / 10 \%$ waste, $5 \%$ in the maximum deflection for the PP/10\%waste, and $70 \%$ in the flexural modulus PP/40\%waste, without compatibilizer.

With the addition of up to $5 \%$ compatibilizer, an increase in tension and maximum deflection was observed. This result indicated that there was probable wetting and mechanical adhesion between the matrix-particle, as well as chemical interactions through polar groups in the structure of the polypropylene grafted with maleic anhydride with the hydroxyls of the cellulosic surface, which demonstrated improvements in the mechanical properties. About formulations with $10 \%$ of compatibilizer there was no significant difference for Eucalyptus but the flexural modulus increased with $40 \%$ Pinus, which may be related to the aspect ratio of the material.

The photomicrographs show that the not compatibilized composites had lower matrix-particle transition than the compatibilized composites. These photomicrographs corroborated with the results obtained previously, in which the compatibilized formulations presented better performance compared to the not compatibilized samples. Figures 8 through 11 show fracture specimens morphologies from the PP/PPMA/ Eucalyptus composites with different formulations. A predominance of ductile fracture surfaces for the not compatibilized composites and fracture of the fragile type for the compatibilized ones was observed, according to results in traction. The ellipses indicated the detachment of the dispersed phase of the unmodified thermoplastic matrix in Fig. 8 and the evident matrix-particle adhesion with the use of PPMA, according to Figs. 9 through 11 . 


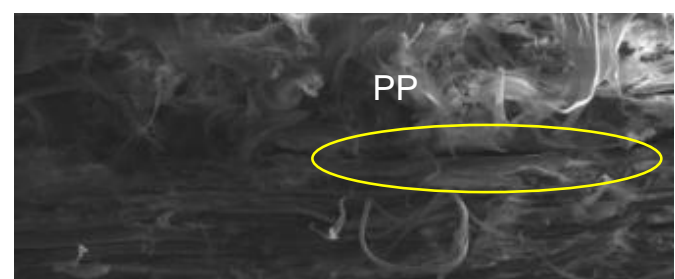

Eucalyptus

$20 \mu \mathrm{m}$

(a)

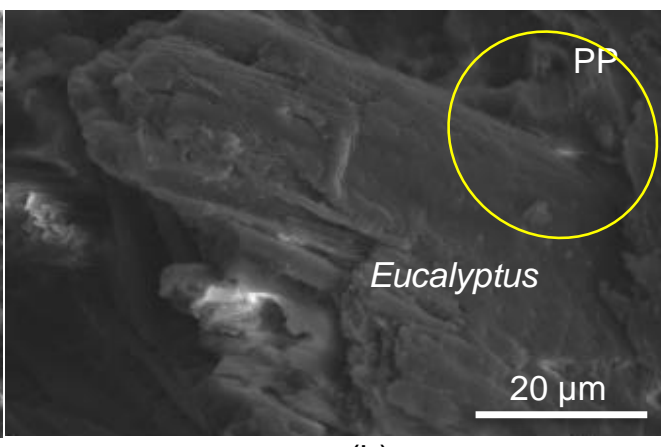

(b)

Fig. 8. Morphology of fracture surfaces of injected specimens of composites PP/20\% Eucalyptus (a) and PP/40\%Eucalyptus (b)

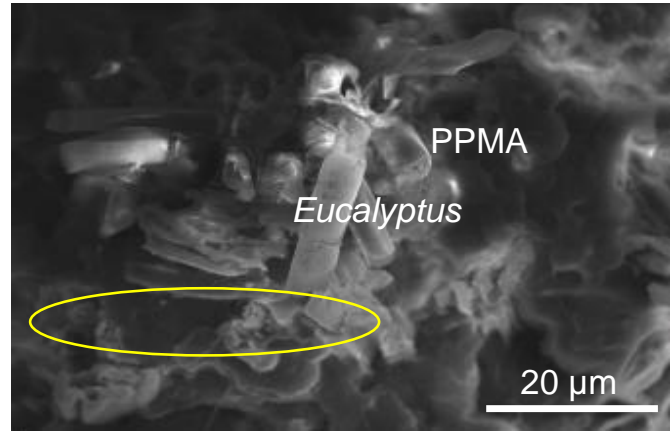

(a)

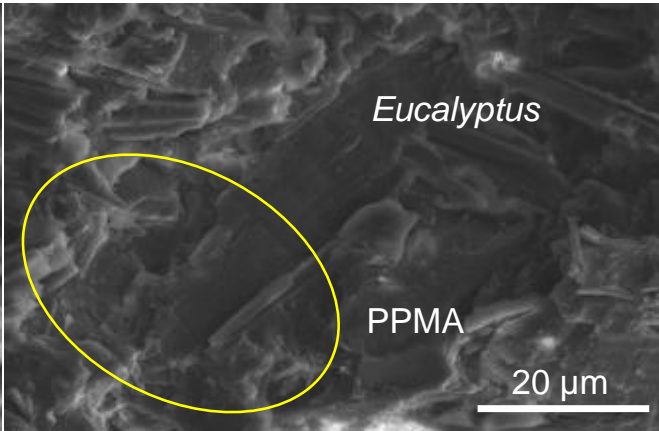

(b)

Fig. 9. Morphology of fracture surfaces of injected specimens of composites PP/1\%PPMA/20\%Eucalyptus (a) and PP/1\%PPMA/40\%Eucalyptus (b)

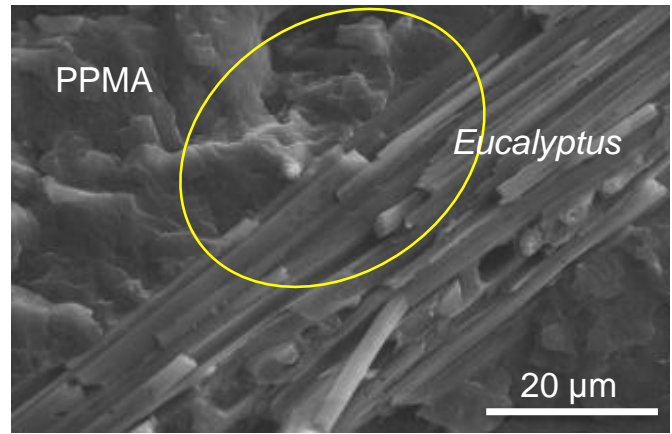

(a)

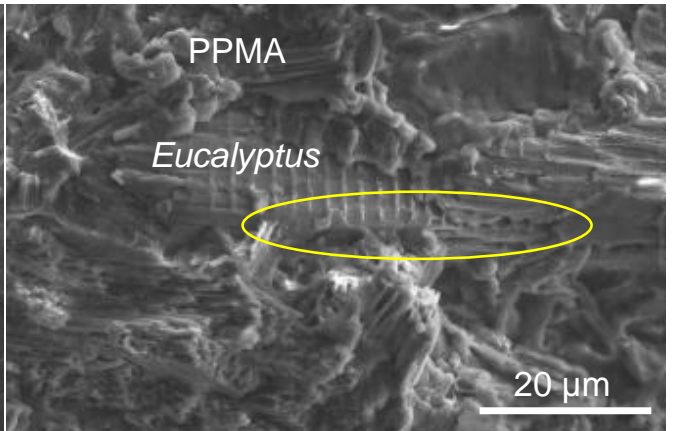

(b)

Fig. 10. Morphology of fracture surfaces of injected specimens of composites PP/5\%PPMA/20\%Eucalyptus (a) and PP/5\%PPMA/40\%Eucalyptus (b) 


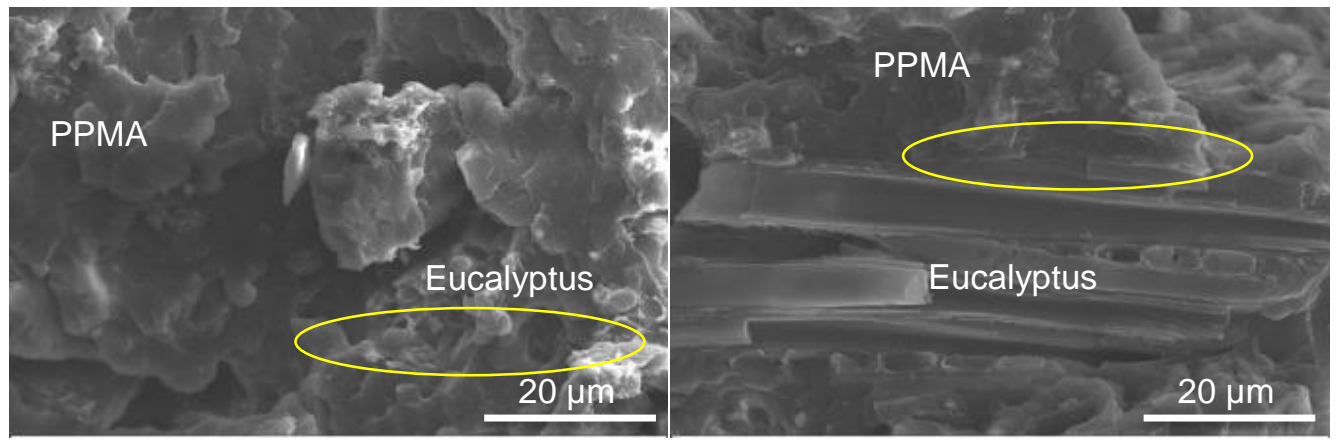

(a)

(b)

Fig. 11. Morphology of fracture surfaces of injected specimens of composites PP/10\%PPMA/20\%Eucalyptus (a) and PP/10\%PPMA/40\%Eucalyptus (b)

The scanning electron micrographs of the tensile fracture specimens of the PP/PPMA/Pinus composites with different formulations are shown in Figs. 12 through 15. Looking at Fig. 12, it was possible to identify that voids and particles detached from the polymer matrix without the added compatibilizer. This showed little affinity between the phases, resulting in poor matrix-particle anchoring. Figures 13 through 15 illustrate a great adhesion between the polymer matrix and the reinforcement with compatibilizing. According to Bledzki and Gassan (1999) and Hristov et al. (2004), polypropylene composites with wood particles, in the presence of compatibilizer, allow the production of composites with better dispersion of the waste to the polymer matrix, resulting in good wettability between phases.

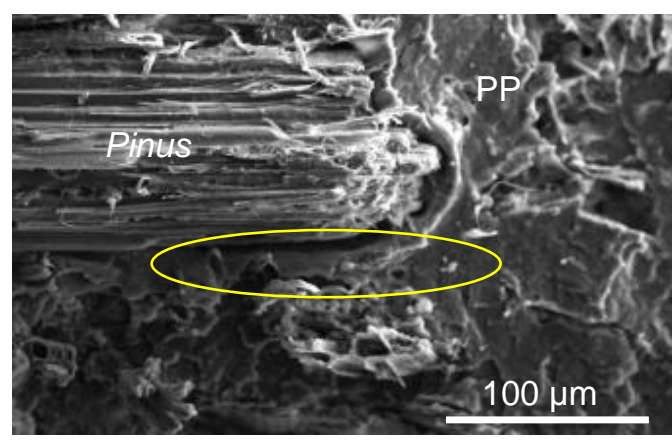

(a)

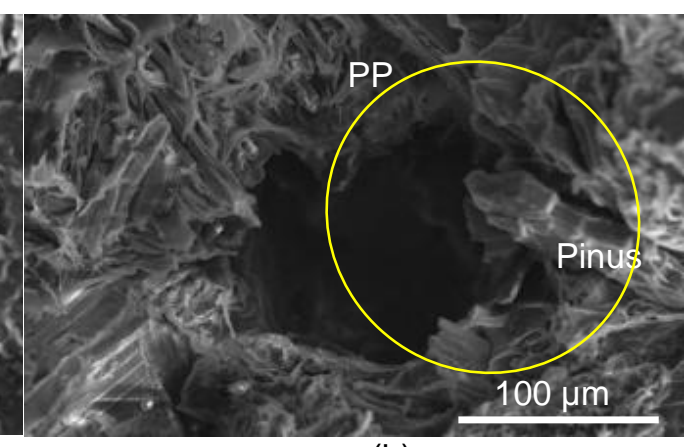

(b)

Fig. 12. Morphology of fracture surfaces of injected specimens of composites PP/20\%Pinus (a) and $\mathrm{PP} / 40 \%$ Pinus (b)

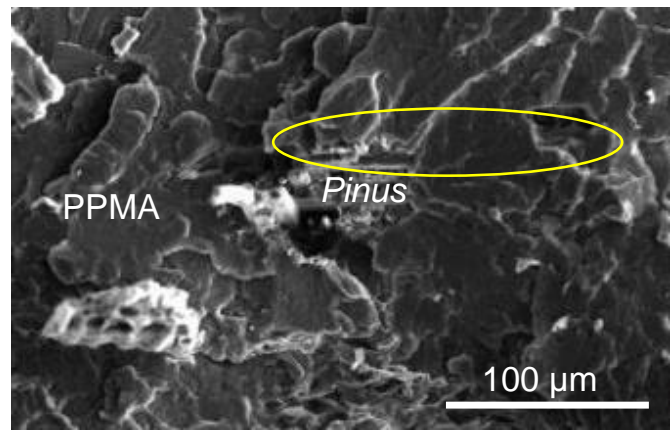

(a)

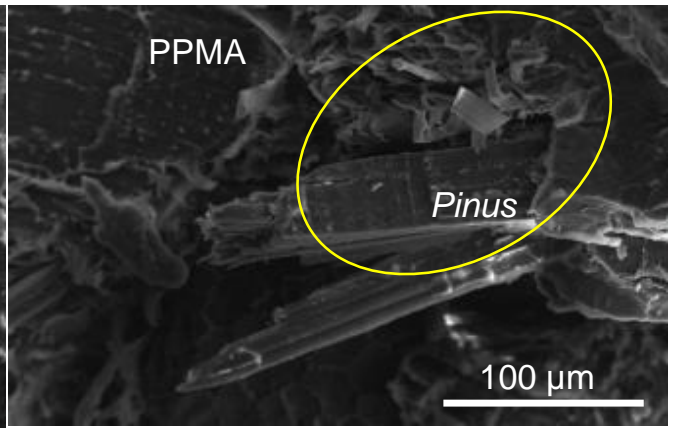

(b)

Fig. 13. Morphology of fracture surfaces of injected specimens of composites PP/1\%PPMA/20\%Pinus (a) and PP/1\%PPMA $/ 40 \%$ Pinus (b) 


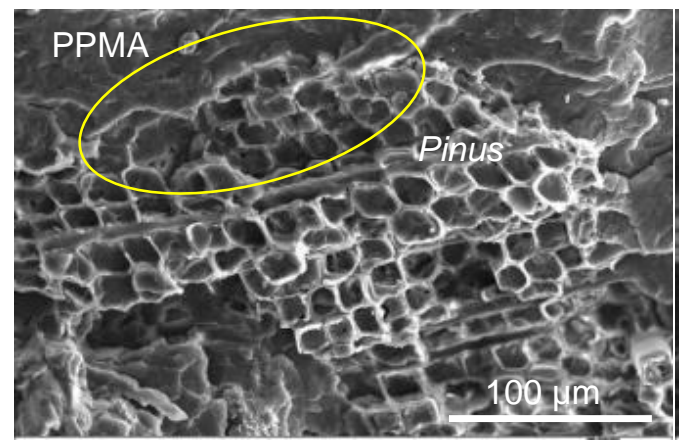

(a)

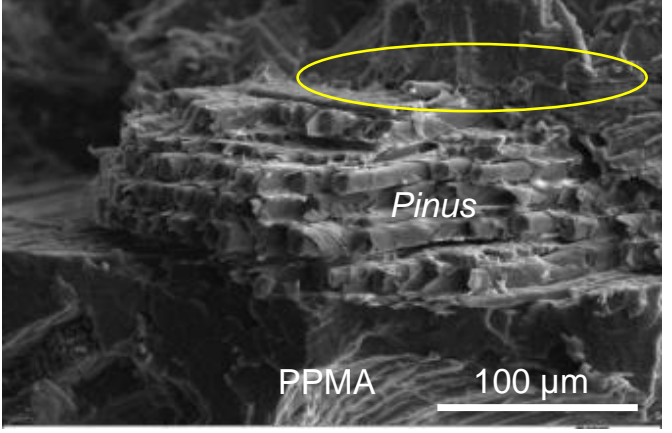

(b)

Fig. 14. Morphology of fracture surfaces of injected specimens of composites PP/5\%PPMA/20\%Pinus (a) and PP/5\%PPMA/40\%Pinus (b)

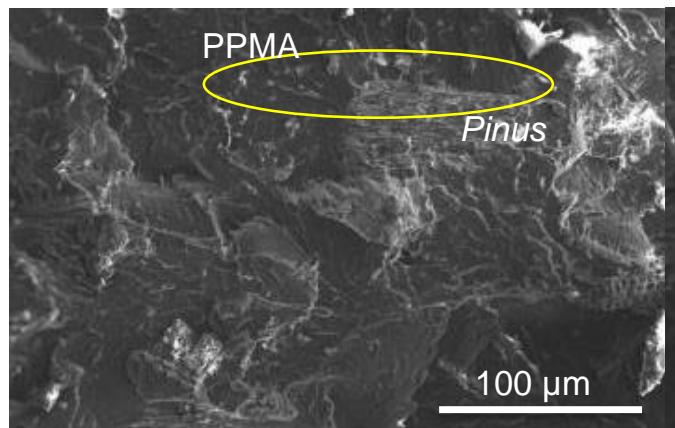

(a)

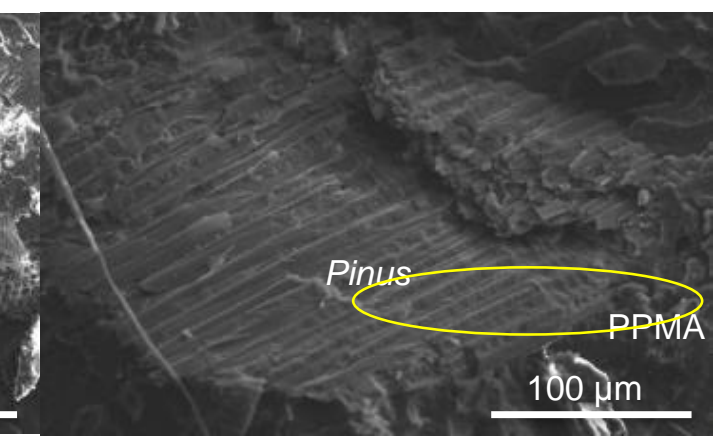

(b)

Fig. 15. Morphology of fracture surfaces of injected specimens of composites PP/10\%PPMA/20\%Pinus (a) and PP/10\%PPMA/40\%Pinus (b)

Table 1 presents the thermal properties of the PP/PPMA/Eucalyptus and PP/PPMA/Pinus composites, compatibilized and not compatibilized.

Table 1. Melt Temperature $\left(T_{\mathrm{m}}\right)$, Melt Enthalpy $\left(\Delta H_{\mathrm{m}}\right)$, and Percent Crystallinity $\left(X_{c}\right)$ of Virgin Polymer and PP/Eucalyptus and PP/Pinus Composites

\begin{tabular}{|c|c|c|c|c|c|c|}
\hline \multirow[b]{2}{*}{ Samples } & \multicolumn{3}{|c|}{ Eucalyptus } & \multicolumn{3}{|c|}{ Pinus } \\
\hline & $\begin{array}{c}T_{\mathrm{m}} \\
(\stackrel{\circ}{\mathrm{C}})\end{array}$ & $\begin{array}{c}\Delta H_{\mathrm{m}} \\
\left(\mathrm{J} \mathrm{g}^{-1}\right)\end{array}$ & $\begin{array}{c}X_{\mathrm{c}} \\
(\%)\end{array}$ & $\begin{array}{c}T_{\mathrm{m}} \\
\left({ }^{\circ} \mathrm{C}\right)\end{array}$ & $\begin{array}{c}\Delta H_{\mathrm{m}} \\
\left(\mathrm{J} \mathrm{g}^{-1}\right)\end{array}$ & $\begin{array}{c}X_{\mathrm{c}} \\
(\%)\end{array}$ \\
\hline Virgin PP & 167.1 & 85.22 & 40.8 & 167.1 & 85.22 & 40.8 \\
\hline \multicolumn{7}{|c|}{ PP/waste } \\
\hline $10 \%$ & 167.1 & 67.57 & 35.9 & 168.7 & 65.46 & 34.8 \\
\hline $20 \%$ & 167.5 & 64.40 & 38.5 & 167.8 & 63.98 & 38.2 \\
\hline $30 \%$ & 167.2 & 54.35 & 37.1 & 168.0 & 56.91 & 38.9 \\
\hline $40 \%$ & 167.3 & 49.44 & 39.4 & 167.5 & 45.70 & 36.4 \\
\hline \multicolumn{7}{|c|}{ PP/1\%PPMA/waste } \\
\hline $20 \%$ & 167.7 & 64.46 & 38.6 & 167.9 & 66.18 & 39.6 \\
\hline $40 \%$ & 166.7 & 50.85 & 40.5 & 167.4 & 49.08 & 39.1 \\
\hline \multicolumn{7}{|c|}{ PP/5\%PPMA/waste } \\
\hline $10 \%$ & 167.2 & 66.47 & 35.3 & 168.2 & 74.10 & 39.4 \\
\hline $20 \%$ & 166.3 & 56.19 & 33.6 & 166.9 & 62.61 & 37.4 \\
\hline $30 \%$ & 166.0 & 46.52 & 31.8 & 167.4 & 56.50 & 38.6 \\
\hline $40 \%$ & 166.2 & 39.72 & 31.7 & 167.0 & 49.64 & 39.6 \\
\hline \multicolumn{7}{|c|}{ PP/10\%PPMA/waste } \\
\hline $20 \%$ & 164.3 & 57.17 & 34.2 & 167.8 & 63.79 & 38.1 \\
\hline $40 \%$ & 166.3 & 49.78 & 39.7 & 166.4 & 46.34 & 37.0 \\
\hline
\end{tabular}


Table 1 shows that for the second heating cycle there were no noticeable variations in the melt temperature of the polypropylene in the presence of waste and compatibilizer for the varying concentrations. Studies conducted by Luyi and Kecheng (2001) using polypropylene rice husks, Kuruvilla and Mattoso (2002) using cellulose microfiber and sisal in a PP matrix, Correa et al. (2003) using three types of particulate waste of polypropylene Pinus wood for compatibilized and not compatibilized mixtures with PPMA, and Joseph et al. (2003) using short sisal fibers in PP, also showed that the melt temperature of the polypropylene $\left(T_{\mathrm{m}}\right)$ remained practically unchanged with an increased percentage of cellulosic filler in the absence and presence of PPMA.

The melting enthalpy of the virgin $\mathrm{PP}\left(\Delta H_{\mathrm{m}}\right)$ in the composites showed a decrease with the addition of cellulosic filler, indicating an inhibitory effect on the crystallization of polypropylene. This showed that the addition of vegetable charges altered the crystallinity of the matrix, interfering in the mechanical properties of the composite materials.

It was observed that the addition of the particulate filler to the PP decreased the crystallinity of the polymer matrix for any series of the composites studied; that is, the presence of PPMA also showed no remarkable influence in the sense of increasing the crystallinity of the polypropylene. Correa et al. (2003) also found that although thermoplastic matrix reinforcement occurs, the crystallinity of the resin tends to decrease in the presence of cellulosic filler, which probably decreases the growth of the crystals. These results indicated that the barrier capacity of the load influenced the effects of the mechanical behavior through the change in crystallinity.

\section{CONCLUSIONS}

1. The addition of loads of Eucalyptus and Pinus particulates to the polypropylene matrix conferred a reinforcing character to the conjugated materials, and the use of Eucalyptus waste in the formulations produced better effects on the results of mechanical resistance of the composites than the Pinus waste for the same formulations.

2. There was a high gain in the modulus of elasticity with the addition of Eucalyptus and Pinus waste in the polymer matrix and a positive influence on the maximum stress via the use of compatibilizer, which was shown to increase the reinforcing action of the composite materials, promoted by the best transfer of charges between matrix-particle. The improvement of the interfacial adhesion did not interfere in the elongation of the composites. An increase in the flexural modulus occurred with the addition of Eucalyptus and Pinus waste in the polypropylene (PP) matrix and a positive influence on the tension and maximum deflection via the use of maleic anhydride-modified polypropylene (PPMA).

3. In compositions with 5\% PPMA, it was possible to add $30 \%$ to $40 \%$ of Eucalyptus and Pinus waste to obtain a small increase in the resistance of the composite materials compared to the thermoplastic matrix. In general, the use of PPMA was efficient in increasing the maximum stress of the developed composites, which proved a better matrix-reinforcement interfacial interaction. Photomicrographs confirmed the improvement of adhesion when the compatibilizer was used, due to the probable esterification and/or hydrogen bonding reactions at the material's surface. Finally, the degree of crystallinity of the thermoplastic matrix presented a decrease with the 
addition of organic load in the composites compatibilized and not compatibilized, due to the limitation in the movement of the crystals.

\section{ACKNOWLEDGMENTS}

The authors are grateful to the Financier of Studies and Projects (FINEP), the Coordination for the Improvement of Higher Education Personnel (CAPES), and the Foundation for the Support of Research (FAPES) for their financial support. The authors are also grateful to the Post-Graduate Program in Metallurgical and Materials Engineering (PROPEMM) of the Federal Institute of Education, Science and Technology of Espirito Santo (IFES) and to the Post-Graduate Program in Mechanical Engineering (PPGMEC) of the Federal University of Minas Gerais (UFMG) for their physical structure and financial support.

\section{REFERENCES CITED}

Albano, C., Ichazo, M., González, J., Delgado, M., and Poleo, R. (2001). "Effects of filler treatments on the mechanical and morphological behavior of PP+wood flour and PP+sisal fiber," Mater. Res. Innov. 4(5-6), 284-293. DOI: 10.1007/s100190000108

ASTM D638-14 (2014). "Standard test method for tensile properties of plastics," ASTM International, West Conshohocken, PA.

ASTM D790-17 (2017). "Standard test methods for flexural properties of unreinforced and reinforced plastics and electrical insulating materials," ASTM International, West Conshohocken, PA.

ASTM D1921-18 (2018). "Standard test methods for particle size (sieve analysis) of plastic materials," ASTM International, West Conshohocken, PA.

ASTM D3418-15 (2015). "Standard test method for transition temperatures and enthalpies of fusion and crystallization of polymers by differential scanning calorimetry," ASTM International, West Conshohocken, PA.

Bledzki, A. K., and Gassan, J. (1999). "Composites reinforced with cellulose based fibres," Prog. Polym. Sci. 24(2), 221-274. DOI: 10.1016/S0079-6700(98)00018-5

Bledzki, A. K., Letman, M., Viksne, A., and Rence, L. (2005). "A comparison of compounding process and wood type for wood fibre-PP composites," Compos. Part A- Appl. S. 36(6), 789-797. DOI: 10.1016/j.compositesa.2004.10.029

Brazilian Tree Industry (IBÁ) (2016). Relatório IBÁ 2017 [IBÁ Report 2017], IBÁ, Brasilia, Brazil.

Caraschi, J. C., and Leão, A. L. (2002). "Wood flour as reinforcement of polypropylene," Mater. Res. 5(4), 405-409. DOI: 10.1590/S1516-14392002000400003

Clemons, C. M. (2002). "Wood-plastic composites in the United States: The interfacing of two industries," Forest. Prod. J. 52(6), 10-18.

Correa, C. A., Fonseca, C. N. P., Neves, S., Razzino, C. A., and Hage, E. (2003). "Compósitos termoplásticos com madeira [Wood-plastic composites]," Polímeros. 13(3), 154-165. DOI: 10.1590/S0104-14282003000300005 
Dai, D., and Fan, M. (2014). "Wood fibres as reinforcements in natural fibre composites: Structure, properties, processing and applications," Natural Fibre Composites: Materials, Processes and Properties 2014, 3-65. DOI: 10.1533/9780857099228.1.3

El-Sabbagh, A. (2014). "Effect of coupling agent on natural fibre in natural fibre/polypropylene composites on mechanical and thermal behavior," Compos. Part B-Eng. 57(1), 126-135. DOI: 10.1016/j.compositesb.2013.09.047

Haq, S., and Srivastava, R. (2017). "Wood polypropylene (PP) composites manufactured by mango wood waste with virgin or recycled PP: Mechanical, morphology, melt flow index and crystalline behaviour," J. Polym. Environ. 25(3), 640-648. DOI: 10.1007/s10924-016-0845-9

Hillig, E., Iwakiri, S., Andrade, M. Z., and Zattera, A. J. (2008). "Caracterização de compósitos produzidos com polietileno de alta densidade (HDPE) e serragem da indústria moveleira [Characterization of composites made from high density polythylene (HDPE) and furniture industry sawdust]," Rev. Árvore 32(2), 299-310. DOI: $10.1590 / \mathrm{S} 0100-67622008000200013$

Hirayamaa, D., Saron, C., Botelho, E. C., Costa, M. L., and Ancelotti, Jr., A. C. (2017). "Polypropylene composites manufactured from recycled carbon fibers from aeronautic materials waste," Mater. Res. 20(2), 519-525. DOI: 10.1590/1980-5373mr-2016-1022.

Hristov, V. N., Lach, R., and Grellmann, W. (2004). "Impact fracture behavior of modified polypropylene/wood fiber composites," Polym. Test. 23(5), 581-589. DOI: 10.1016/j.polymertesting.2003.10.011

ISO 13322-1 (2014). "Particle size analysis - Image analysis methods - Part 1: Static image analysis methods."

Joseph, P. V., Mathew, G., Joseph, K., Groeninckx, G., and Thomas, S. (2003). "Dynamic mechanical properties of short sisal fibre reinforced polypropylene composites," Compos. Part A-Appl. S. 34(3), 275-290. DOI: 10.1016/S1359835X(02)00020-9

Keener, T. J., Stuart, R. K., and Brown, T. K. (2004). "Maleated coupling agents for natural fibre composites," Compos. Part A-Appl. S. 35(3), 357-362. DOI: 10.1016/j.compositesa.2003.09.014

Kim, S. J., Moon, J. B., Kim, G. H., and Ha, C. S. (2008). "Mechanical properties of polypropylene/natural fiber composites: Comparison of wood fiber and cotton fiber," Polym. Test. 27(7), 801-806. DOI: 10.1016/j.polymertesting.2008.06.002

Kuruvilla, J., and Mattoso, L. H. C. (2002). "Recent developments in natural fibre based polymer composites," Natural Polymers and Composites IV 1(1), 443-454.

Leão, A. L., Ferrão, P. C., and Souza, S. F. (2009). "State of the art for extrusion and injection molding FPC - fiber plastics composites in Brazil," Int. J. Mater. Prod. Tec. 36(1-4), 134-154. DOI: 10.1504/IJMPT.2009.027826

Leong, Y. W., Thitithanasarn, S., Yamada, K., and Hamada, H. (2014). "Compression and injection molding techniques for natural fiber composites," Natural Fibre Composites: Materials, Processes and Properties 8(1), 216-232. DOI: 10.1533/9780857099228.1.3

López-Manchado, M. A., Biagiotti, J., and Kenny, J. M. (2002). "Comparative study of the effects of different fibers on the processing and properties of polypropylene matrix composites," J. Thermoplast. Compos. 15(4), 337-353. DOI: 10.1300/J395v01n03_03 
Luyi, S., and Kecheng, G. (2001). "Silicon-based materials from rice husk and their applications," Ind. Eng. Chem. 40(25), 5861-5877. DOI: 10.1021/ie010284b

Malkapuram, R., Kumar, V., and Negi, Y. S. (2009). "Recent development in natural fiber reinforced polypropylene composites," J. Reinf. Plast. Compos. 28(10), 11691189. DOI: $10.1177 / 0731684407087759$

Nuñez, A. J., Sturm, P. C., Kenny, J. M., Aranguren, M. I., Marcovich, N. E., and Reboredo, M. M. (2003). "Mechanical characterization of polypropylene-wood flour composites," J. Appl. Polym. Sci. 88(6), 1420-1428. DOI: 10.1002/app.11738

Paes, J. B., Nunes, S. T., Lahr, F. A. R., Nascimento, M. F., and Lacerda, R. M. A. (2011). "Qualidade de chapas de partículas de Pinus elliottii coladas com resina poliuretana sob diferentes combinações de pressão e temperature [Quality of Pinus elliottii particleboards boned with polyurethane adhesive under various combinations of temperature and pressure]," Ciênc. Florest. 21(3), 551-558. DOI: 10.5902/198050983812

Parente, R. A., and Pinheiro, L. M. (2008). "Plásticos reciclados para elementos estruturais [Recycled plastics for structural elements]," Cadernos de Engenharia de Estruturas 10(47), 75-95.

Pukánszky, B. (2005). "Interfaces and interphases in multicomponent materials: Past, present, future," Eur. Polym. J. 41(4), 645-662. DOI: 10.1016/j.eurpolymj.2004.10.035

Qiu, W., Zhang, F., Endo, T., and Hirotsu, T. (2003). "Preparation and characteristics of composites of high-crystalline cellulose with polypropylene: Effects of maleated polypropylene and cellulose content," J. Appl. Polym. Sci. 87(2), 337-345. DOI: 10.1002/app.11446

Rosário, F., Pachekoski, W. M., Silveira, A. P. J., Santos, S. F., Júnior, H. S., and Casarin, S. A. (2011). "Resíduos de sisal como reforço em compósitos de polipropileno virgem e reciclado [Virgin and recycled polypropylene composites reinforced with sisal by-product]," Polímeros. 21(2), 90-97. DOI: 10.1590/S010414282011005000021

Stark, N. M. (1999). "Wood fiber derived from scrap pallets used in polypropylene composites," Forest. Prod. J. 49(6), 39-46.

Yamaji, F. M., and Bonduelle, A. (2004). "Utilização da serragem na produção de compósitos plástico-madeira [Use of sawdust in wood-plastic composites production]," Revista Floresta 34(1), 59-66. DOI: 10.5380/rf.v34i1.2375

Yeh, S. K., Kim, K. J., and Gupta, R. K. (2013). "Synergistic effect of coupling agents on polypropylene-based wood-plastic composites," J. Appl. Polym. Sci. 127(2), 10471053. DOI: 10.1002/app.37775

Article submitted: February 1, 2019; Peer review completed: April 12, 2019; Revisions accepted: April 26, 2019; Published: April 29, 2019.

DOI: 10.15376/biores.14.2.4774-4791 